\title{
Dietary Omega-3 Fatty Acids Deficiency Affects the Glutamatergic Transport System in Rat Retina: Modulatory Effects after High Intraocular Pressure
}

\author{
Letícia V. Siqueira ${ }^{1}$, Eduardo P. Rico ${ }^{1}$, Mário C. Bulla ${ }^{1}$, Luciano Bellini ${ }^{1}$, Luiz C. L. Silveira ${ }^{2}$, \\ Lúcia Vinadé $^{3}$, Diogo O. Souza ${ }^{1}$, Júlia D. Moreira ${ }^{4^{*}}$ \\ ${ }^{1}$ Biochemistry Department, Basic Sciences of Health Institute, Federal University of Rio Grande do Sul, Porto Alegre, Brazil; ${ }^{2}$ Phy- \\ siology Department, Biological Science Center, Federal University of Pará, Belém, Brazil; ${ }^{3}$ Master Graduation Program in Biological \\ Sciences, Campus São Gabriel, Federal University of Pampa-UNIPAMPA, São Gabriel, Brazil; ${ }^{4}$ Department of Nutrition, Health \\ Sciences Centre, Federal University of Santa Catarina, Campus Universitário Trindade, Florianópolis, Brazil. \\ Email: ${ }^{*}$ juliamoreira@gmail.com
}

Received May $25^{\text {th }}, 2013$; revised June $25^{\text {th }}, 2013$; accepted July $4^{\text {th }}, 2013$

Copyright (C) 2013 Letícia V. Siqueira et al. This is an open access article distributed under the Creative Commons Attribution License, which permits unrestricted use, distribution, and reproduction in any medium, provided the original work is properly cited.

\begin{abstract}
Glutamate excitotoxicity has been postulated as a putative mechanism involved in the physiopathology of glaucoma, a disease that can cause retinal cell damage. Thus, the modulation of glutamatergic parameters is a putative therapeutic target to prevent excitotoxic retinal injury. Here, we investigated the effect of dietary omega- 3 fatty acids $(\omega 3)$ in the retinal glutamate transport system in basal and ischemic conditions. Female Wistar rats were divided into two groups: $\omega 3$ diet ( $\omega 3$ group) and $\omega 3$ deficient-diet (D group). Their pups, at 60 days old, were used for the experiments. Retinal ischemia, a mechanism involved in the physiopathology of glaucoma, was induced by high intraocular pressure (HIOP, 140 - $180 \mathrm{mmHg}$ for $45 \mathrm{~min}$ ) to impair retinal blood flow. Analyses were performed 7 days after ischemia. The D group showed a decreased glutamate uptake in basal conditions and after HIOP when compared to the $\omega 3$ group. After HIOP, there was a decrease in glutamate uptake in the $\mathrm{D}$ group that was not observed in the $\omega 3$ group $(p<0.005)$. Concerning glutamate transporters, the $\omega 3$ group presented higher levels of GLT-1 compared to the D group in basal and ischemic conditions. After HIOP, EAAC1 was increased in both groups, while GLT-1 increased only in the D group, compared to basal levels. GLAST and EAAT5 presented no alterations. The modulation of the glutamatergic system by dietary $\omega 3$ fatty acids points to a potential mechanism by which $\omega 3$ PUFAs exert beneficial effects in the retina.
\end{abstract}

Keywords: N-3 PUFAs; Retina; Ischemia; HIOP; Glaucoma; Glutamate Transporters

\section{Introduction}

Glutamate is the major excitatory neurotransmitter in the mammalian central nervous system (CNS), participating in retinal development and physiology, and consequently in visual processes $[1,2]$. However, elevated levels of extracellular glutamate (excitotoxicity) have been implicated in the pathophysiology of ophthalmic disorders, such as glaucoma, diabetes and inherited photoreceptor degeneration [2-6]. Glutamate transporters are responsible for maintaining the extracellular glutamate concentration below toxic levels, and they play a key role in regulating the balance between physiological and pathological signaling through glutamatergic receptors $[2,7]$.

${ }^{*}$ Corresponding author.
In the retina, 5 distinct glutamate transporters have been identified: GLAST has been mainly associated with the glial Müller cells [8,9]; GLT-1 is mainly associated with cone photoreceptors and cone bipolar cells [10]; EAAC1 is especially present in horizontal cells, some amacrine cells and ganglion cells [11,12]; EAAT5 is predominantly associated with photoreceptors and bipolar cells $[13,14]$; and EAAT4 is especially associated with astrocytes, being colocalized with GLAST in retinal tissue, and with the pigment epithelium $[15,16]$. Moreover, it was recently demonstrated that these transporters could present specific splice variants, as observed for EAAT5 and GLAST $[17,18]$, which could have different properties and functions in retina.

Under normal conditions, retinal glutamate transport is 
mainly performed by GLAST-mediated uptake into Müller cells $[2,8,13]$. However, under pathological conditions, the Müller cells' uptake of glutamate is reduced [19-21], which can affect cellular integrity [22,23]. High intraocular pressure (HIOP) in experimental models of glaucoma impairs GLAST activity, resulting in the accumulation of glutamate in retinal cells, such as ganglion cells; this reduction in glutamate uptake by Müller cells has been related to the excitotoxic damage to the retina $[7,14,22]$. It was also postulated that EAAT4 has an important role in glutamate uptake in the retina [16].

Omega-3 polyunsaturated fatty acids ( $\omega 3$ fatty acids), largely docosahexaenoic acid (DHA 22:6 $\omega 3$ ), are essential polyunsaturated fatty acids (PUFA) in the retina [2426]. DHA has been found composing $43 \%$ of the phospholipids in the retinal photoreceptors. In mammals, dietary deficiency in $\omega 3$ fatty acids results in alterations in the retinal PUFA pattern, with a significant decrease in DHA (by approximately $40 \%$ of normal levels) $[27,28]$, which can affect visual function [29,30]. DHA is essential for development and differentiation of photoreceptors and for protection against damage to retinal cells $[26,31$, 32]. Recently, it was demonstrated that DHA can prevent retinal cell damage caused by ischemia and its complications [33,34]. Dietary sources of $\omega 3$ PUFAs include mainly fatty fishes (salmon, tuna, and sardines). A poor dietary source of $\omega 3$ fatty acids is peanut oil, which is used to induce $\omega 3$ deficiencies in experimental studies.

Despite all investigations, little is known about the influence of $\omega 3$ fatty acids on the retina, especially concerning the glutamatergic system in basal conditions and in retinal injury models. Thus, in the present study, we used HIOP to investigate whether dietary $\omega 3$ fatty acids deficiency affects the glutamate transporter system of the retina under basal and ischemic conditions.

\section{Materials and Methods}

\subsection{Animals and Diets}

Female Wistar rats were housed in standard conditions $\left(21^{\circ} \mathrm{C}-22^{\circ} \mathrm{C}, 12 \mathrm{~h}\right.$ dark-light cycle, food and water $a d$ libitum). The dietary model (Tables $\mathbf{1}$ and $\mathbf{2}$ ) used in this study has been previously described [35]. Briefly, 2 weeks before mating, the female rats were divided into two groups: $\omega 3 \operatorname{diet}(\omega 3)$ and $\omega 3$ deficientdiet (D). These diets were isocaloric, containing $8 \%$ total fat and differed only in the fatty acid composition. After weaning, the pups were maintained on the same diet as their dams until adulthood (60 days old), when experiments were conducted. For the experiments, only male rats were used. All experiments were in agreement with the Committee on Care and Use of Experimental Animal Resources, UFRGS, Brazil. In relation to fatty acids composition of
Table 1. Nutritional composition of the diets.

\begin{tabular}{ccc}
\hline & $\omega 3$ diet (\%) & D diet (\%) \\
\hline Casein & 22 & 22 \\
Corn starch & 42 & 42 \\
D-L-Methionin & 0.16 & 0.16 \\
Sucrose & 21 & 21 \\
Celulose & 2 & 2 \\
Mineral salt mix & 4 & 4 \\
Vitamin mix & 1 & 1 \\
Peanut oil & 0 & 8 \\
Corn oil & 7 & 0 \\
Fish oil & 1 & 0
\end{tabular}

${ }^{a}$ Mineral salt mixture: $\mathrm{mg} / 100 \mathrm{~g}$ of diet: $\mathrm{NaCl}, 557 ; \mathrm{KI}, 3.2 ; \mathrm{KH}_{2} \mathrm{PO}_{4}, 1556$; $\mathrm{MgSO}_{4}, 229 ; \mathrm{CaCO}_{3}, 1526 ; \mathrm{FeSO}_{4}-7 \mathrm{H}_{2} \mathrm{O}, 108 ; \mathrm{MnSO}_{4}-\mathrm{H}_{2} \mathrm{O}, 16 ; \mathrm{ZnSO}_{4}-$ $7 \mathrm{H}_{2} \mathrm{O}, 2.2 ; \mathrm{CuSO}_{4}-5 \mathrm{H}_{2} \mathrm{O}, 1.9 ; \mathrm{CoCl}-6 \mathrm{H}_{2} \mathrm{O}, 0.09 ;{ }^{b}$ Vitamin mixture: $\mathrm{mg} / 100 \mathrm{~g}$ of diet: Vitamin A, 4; Vitamin D, 0.5; Vitamin E, 10; Menadione, 0.5; Choline, 200; PABA, 10; Inositol, 10; Niacine, 4; Pantothenic acid, 4; Riboflavin, 0.8; Thiamin, 0.5; Folic acid, 0.2; Biotin, 0.04; Vitamin B12, 0.003 .

Table 2. Fatty acids composition of the dietary lipids.

\begin{tabular}{|c|c|c|}
\hline & $\omega 3 \operatorname{diet}(\%)$ & $\mathrm{D} \operatorname{diet}(\%)$ \\
\hline \multicolumn{3}{|l|}{ Saturated } \\
\hline $\mathrm{C} 14: 0$ & 0.10 & 0.10 \\
\hline $\mathrm{C} 16: 0$ & 10.90 & 11.10 \\
\hline $\mathrm{C} 17: 0$ & 0.10 & 0.01 \\
\hline $\mathrm{C} 18: 0$ & 2.00 & 2.40 \\
\hline $\mathrm{C} 20: 0$ & 0.50 & 1.30 \\
\hline $\mathrm{C} 22: 0$ & 0.10 & 2.90 \\
\hline $\mathrm{C} 24: 0$ & 0.01 & 1.50 \\
\hline \multicolumn{3}{|c|}{ Monounsaturated } \\
\hline C16:1 & 0.20 & 0.20 \\
\hline $\mathrm{C} 17: 1$ & 0.00 & 0.01 \\
\hline C18:1 & 25.40 & 46.70 \\
\hline C20:1 & 0.02 & 1.60 \\
\hline $\mathrm{C} 22: 1$ & 0.00 & 0.01 \\
\hline $\mathrm{C} 24: 1$ & 0.00 & 0.00 \\
\hline \multicolumn{3}{|c|}{ Polyunsatutared } \\
\hline $\mathrm{C} 18: 2 \omega 6$ & 56.60 & 32.00 \\
\hline $\mathrm{C} 18: 3 \omega 3$ & 1.20 & 0.01 \\
\hline $\mathrm{C} 20: 5 \omega 3$ & 1.25 & 0.00 \\
\hline $\mathrm{C} 22: 6 \omega 3$ & 2.50 & 0.00 \\
\hline
\end{tabular}


the dietary lipids, it was estimated by fatty acids composition of the oil sources used in each specific diet (peanut oil and corn oil as previously described [43]; fish oil as manufacturer's information, Naturalis, Brazil).

\subsection{Retinal Ischemia Model}

To produce an ischemic insult by high intraocular pressure (HIOP) in the retina, animals were anesthetized with ketamine $(100 \mathrm{mg} / \mathrm{kg})$ and xylazine $(12 \mathrm{mg} / \mathrm{kg})$. The anterior chamber of one eye was cannulated using a 30gauge needle connected to a reservoir of sterile balanced salt solution, which was infused into the eye by a perfusion bomb. The pressure was monitored to control the blood flow obstruction (140 - $180 \mathrm{mmHg}$ ) [36]. After 45 min of ischemia, animals were returned to standard conditions (12 h light/dark cycle, food and water ad libitum) for 7 days, when experiments were performed. The other eye was used as a control.

\subsection{Retinal $\left[{ }^{3} \mathrm{H}\right]$ Glutamate Uptake}

Retinal glutamate uptake was standardized before the experiments concerning time and glutamate concentrations (data not shown). Seven days after ischemia, animals ( $\mathrm{n}=8$ per group) were decapitated and their eyes were immediately removed and humidified with Hank's balanced salt solution (HBSS) containing the following (in $\mathrm{mM}$ ): $137 \mathrm{NaCl}, 0.63 \mathrm{Na}_{2} \mathrm{HPO}_{4}, 4.17 \mathrm{NaHCO}_{3}, 5.36$ $\mathrm{KCl}, 0.44 \mathrm{KH}_{2} \mathrm{PO}_{4}, 1.26 \mathrm{CaCl}_{2}, 0.41 \mathrm{MgSO}_{4}, 0.49 \mathrm{MgCl}_{2}$ and 1.11 glucose, $\mathrm{pH}$ 7.2. Retinas were dissected and pre-incubated at $37^{\circ} \mathrm{C}$ for $15 \mathrm{~min}$ before performing $\left[{ }^{3} \mathrm{H}\right]$ glutamate uptake. After that, retinas were washed twice with $1 \mathrm{~mL}$ HBSS, the medium was replaced, and $100 \mu \mathrm{M}\left[{ }^{3} \mathrm{H}\right]$ glutamate (total uptake) was added. Incubation was stopped after 7 min with 2 ice-cold washes with $1 \mathrm{~mL}$ of HBSS, immediately followed by the addition of $1 \mathrm{~N} \mathrm{NaOH}$. Retinas were then incubated overnight. The $\mathrm{Na}^{+}$-independent uptake was measured with the same protocol described above, with differences in the temperature (on ice, $4^{\circ} \mathrm{C}$ ) and medium composition $(N$-methyl-D-glucamine instead of sodium chloride). $\mathrm{Na}^{+}$-dependent uptake was considered as the difference between the total uptake and the $\mathrm{Na}^{+}$-independent uptake. Incorporated radioactivity was measured using a liquid scintillation counter.

\subsection{Western Blot Analysis}

Retinas were dissected out 7 days after the ischemic episode and immediately homogenized in a $25 \mathrm{mM}$ Hepes solution ( $\mathrm{pH} 7.4$ ) with $0.1 \%$ SDS and protease inhibitor cocktail (Sigma). Samples $(20 \mu \mathrm{g}$ protein/well) were separated in an $8 \%$ SDS-PAGE mini-gel and transferred to a nitrocellulose membrane using a Trans-Blot system (Bio-Rad, São Paulo/SP, Brazil). Membranes were processed as follows: 1) blocking with $5 \%$ bovine serum albumin (Sigma, São Paulo/SP, Brazil) for $2 \mathrm{~h}$; 2) incubation with primary antibody overnight: 1:1000 rabbit antiGLAST, anti-GLT-1, anti-EAAC1 or anti-EAAT5 for glutamate transporters (AlphaDiagnostic International) or 1:2000 mouse anti- $\beta$-Actin (Sigma); 3 ) incubation with horseradish peroxidase-conjugated secondary antibody for rabbit 1:3000 or mouse 1:3000 (Amersham Pharmacia Biotech) for $2 \mathrm{~h}$; 4) chemiluminescence (ECL, Amersham Pharmacia Biotech, São Paulo/SP, Brazil) was detected using X-ray films (Kodak X-Omat, Rochester, NY, USA). The films were scanned, and band intensities were analyzed using Image J software (developed at the US National Institutes of Health and available on the Internet at http://rsb.info.nih.gov/nih-image/). To determine an adequate amount of protein to be assayed, various protein concentrations were carried out in the same gel for each antibody tested.

\subsection{Statistical Analysis}

One-way ANOVA was followed by Tukey's post-hoc test. Values of $p<0.05$ were considered significant. Statistical analysis was performed using SPSS 15.0 software.

\section{Results}

The timepoint of 7 days after HIOP was chosen for the analysis because, in early periods after HIOP, this ischemic model did not cause apparent alterations in glutamate uptake (data not shown). Figure 1 shows the glutamate uptake by the whole retina. The $\omega 3$ fatty acid deprivation decreased the glutamate uptake measured in basal conditions $(p<0.05)$. Remarkably, retinal ischemia

$\left[{ }^{3} \mathrm{H}\right]$ Glutamate uptake

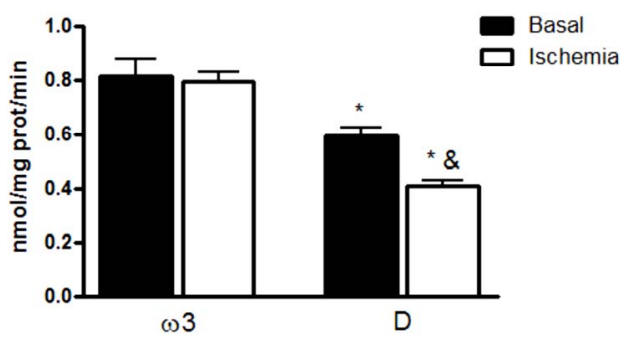

Figure 1. Effect of $\omega 3$ deficiency and ischemia on $\left[{ }^{3} \mathrm{H}\right] \mathrm{glu}-$ tamate uptake by the retina. Experiments were performed 7 days after the ischemic insult. $\omega 3$ ( $\omega 3$ group, $n=8), D(\omega 3$ deficient group, $n=8$ ). Data are expressed as the mean \pm SD. One-way ANOVA followed by Tukey post-hoc was used $\left({ }^{*} p<0.005\right.$ in relation $\omega 3$ groups; ${ }^{\&} p<0.05$ in relation to basal D group). 
decreased the glutamate uptake in the D group $(p<0.05)$ without affecting glutamate uptake in the $\omega 3$ group.

Because $\omega 3$ fatty acids deprivation and retinal ischemia decreased the glutamate uptake by the whole retina, we also evaluated the levels of several glutamate transporters (GLT-1, GLAST, EAAC1, EAAT5) (Figure 2). The glutamate transporters levels were the same under basal conditions in the $\mathrm{D}$ and $\omega 3$ groups, with the exception of the GLT-1 levels, which were lower in the D group than in the $\omega 3$ group $(p<0.05)$. Concerning the retinal ischemia, GLT-1 levels significantly increased only in the D group $(p<0.05)$; EEAC1 levels increased in both ischemic groups $(p<0.05)$. GLAST and EAAT5 levels were not affected by $\omega 3$ fatty acids deprivation or ischemia.

\section{Discussion and Conclusions}

In the present study, we focused on the modulatory effect of $\omega 3$ fatty acids on glutamatergic parameters rather than the prevention of possible morphologic alterations caused by ischemic injury in the retina, which has already been investigated by other authors. We observed that $\omega 3$ fatty acids deprivation decreased the glutamate uptake in
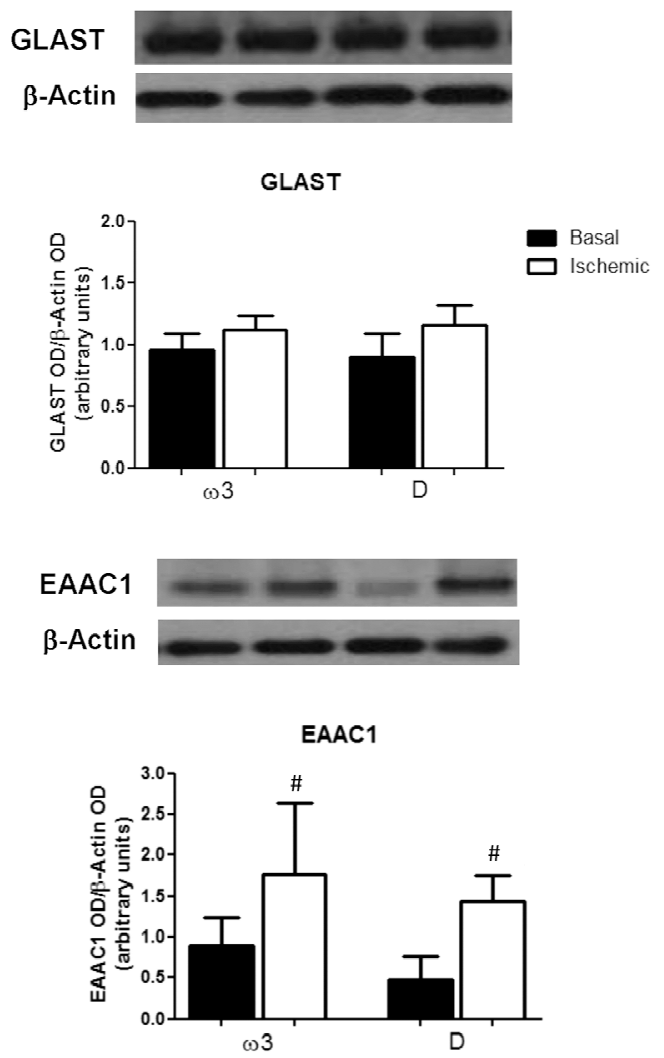

whole retina, which could render the retina more susceptible to ischemic insult. Consistent with this model, HIOP decreased the observed glutamate uptake only in the D group. HIOP increased the levels of GLT1 in the D group and of EEAC1 in both groups. GLAST and EAAT5 levels were not modulated by diets or HIOP.

In the retina, the role of glutamatergic transporters is still not completely understood. It is known that GLAST is the main glutamate transporter responsible for maintaining extracellular glutamate below toxic levels, preventing excitotoxic damage to neuronal cells; however, GLAST activity is impaired during ischemia $[2,6,8,11$, 20]. In the present work, the glutamate uptake activity was affected by $\omega 3$ deficiency. The $\mathrm{D}$ group presented lower glutamate uptake in basal conditions than the $\omega 3$ group did. After HIOP, it was observed that $\omega 3$ fatty acids prevented the decrease in glutamate uptake. However, the reduction of glutamate uptake in the D group was not related to a reduction in GLAST levels because its levels were the same in both groups. Barnett and colleagues also observed no changes in GLAST levels after an ischemic insult, despite the reduction in the glutamate uptake capacity of Müller cells [20]. It has been demonstrated that GLAST activity is also regulated by mem-
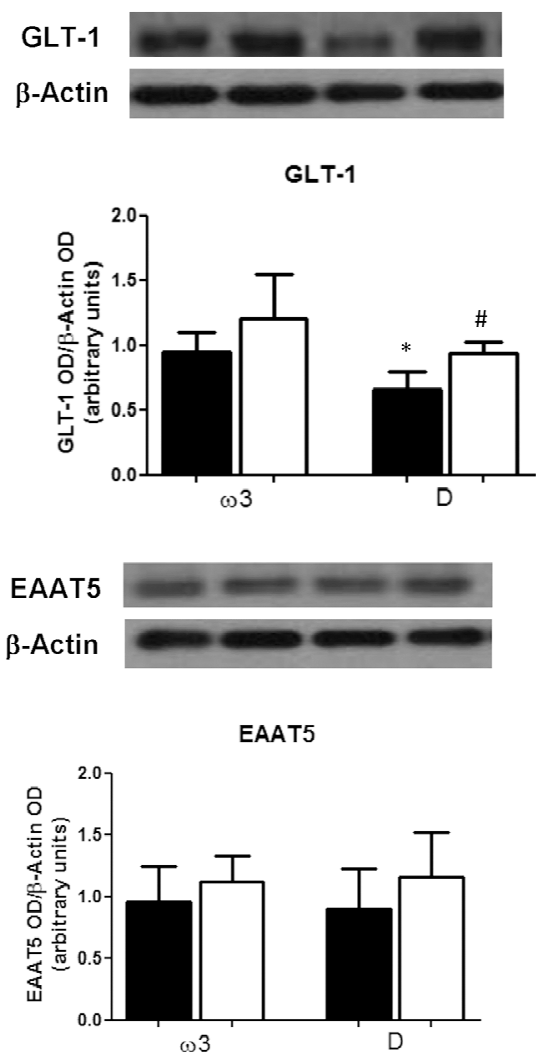

Figure 2. Effect of $\omega 3$ deficiency and ischemia on glutamate transporters levels. Experiments were performed 7 days after the ischemic insult. $\omega 3$ group, $n=6)$, $D(\omega 3$ deficient group, $n=5)$. Data are expressed as the mean \pm SD. One-way ANOVA followed by Tukey post-hoc was used $\left({ }^{*} p<0.05\right.$ in relation to basal $\omega 3$ group; ${ }^{*} p<0.05$ within specific diet group). 
brane potential [37], suggesting that ischemia and $\omega 3$ fatty acids could be modulating this potential and thereby influencing the overall glutamate uptake activity. As glutamate accumulation is excitotoxic to neurons, the maintenance of glutamate removal is essential for preventing cell death in the retina. Our results point to the importance of $\omega 3$ fatty acids in adequate glutamate uptake activity, putatively involved in the resistance to an ischemic insult.

Little is known about the functional significance of GLT-1 expression in the retina, especially under pathological conditions. It has been proposed that GLT-1 could be responsible for maintaining glutamate homeostasis in the retina during ischemia because GLT-1 levels increased during the ischemic period, while GLAST levels presented no variation [38]. Our results reveal that GLT-1 levels increased in the D group 7 days after ischemia, despite the fact that these levels remained lower than in the $\omega 3$ group. We therefore postulate that the higher GLT-1 levels in the $\omega 3$ group could be involved in the prevention of retinal damage caused by a decrease in glutamate uptake.

As for EAAC1, it has been demonstrated that it is localized both synaptically and extrasynaptically [12], but its contribution to glutamate uptake is not clear. EAAC1deficient mice presented spontaneous ganglion cell and optic nerve degeneration [39,40], and their ganglion cells were more vulnerable to oxidative stress [39]. Here, we observed that EAAC1 levels increased in both D and $\omega 3$ groups after ischemia. We postulate that this could be another compensatory mechanism against ischemic damage.

EAAT5 is primarily expressed in the retina $[13,41]$. It has been postulated that EAAT5 presents a high $\mathrm{Cl}^{-}$conductance and is located close to the glutamate release sites, acting as an inhibitory presynaptic receptor and controlling glutamate release [42]. Few studies have evaluated EAAT5 in response to ischemic conditions. It was reported previously that the localization of this transporter was not affected until 60 days after ischemia [14]. In the present work, we observed that EAAT5 levels were neither affected by diets nor ischemia.

In our study, we did not investigate EAAT4 levels; thus, we cannot eliminate the possibility that this transporter could also be related to the $\omega 3$ or ischemic effects observed here.

Our data, in accordance with the literature, indicate that dietary $\omega 3$ fatty acids are relevant to adequate functionality of the glutamate transport system in basal conditions and in retinal ischemia. The data point to a possible relevant therapeutic target in pathologies related to the excitotoxicity of the glutamatergic system in the retina, including glaucoma. Nevertheless, more studies must be performed to elucidate the role of $\omega 3$ fatty acids in retinal functionality.

\section{Acknowledgements}

This work was support by CAPES, FAPERGS, INCT. EN-CNPq/INCT and IBN.Net FINEP/FADESP (Proc. No. 01.06.0842-00). None of the authors has any conflict of interest to disclose. Special thanks to Suzana Wofchuk for the support. In memoriam of Professor Marcos L. S. Perry.

\section{REFERENCES}

[1] A. V. Tzingounis and J. I. Wadiche, "Glutamate Transporters: Confining Runaway Excitation by Shaping Synaptic Transmission," Nature Reviews Neuroscience, Vol. 8, No. 12, 2007, pp. 935-947. doi:10.1038/nrn2274

[2] A. Bringmann, T. Pannicke, B. Biedermann, M. Francke, I. Iandiev, J. Grosche, P. Wiedemann, J. Albrecht and A. Reichenbach, "Role of Retinal Glial Cells in Neurotransmitter Uptake and Metabolism," Neurochemistry International, Vol. 54, No. 3-4, 2009, pp. 143-160.

doi:10.1016/j.neuint.2008.10.014

[3] J. Ambati, K. V. Chalam, D. K. Chawla, C. T. D'Angio, E. G. Guillet, S. J. Rose, R. E. Vanderlinde and B. K. Ambati, "Elevated Gamma-Aminobutyric Acid, Glutamate, and Vascular Endothelial Growth Factor Levels in the Vitreous of Patients With Proliferative Diabetic Retinopathy," Archives of Ophthalmology, Vol. 115, No. 9, 1997, pp. 1161-1166. doi:10.1001/archopht.1997.01100160331011

[4] D. E. Brooks, G. A. Garcia, E. B. Dreyer, D. Zurakowski and R. E. Franco-Bourland, "Vitreous Body Glutamate Concentration in Dogs with Glaucoma," American Journal of Veterinary Research, Vol. 58, No. 8, 1997, pp. 864-867.

[5] K. R. Martin, H. Levkovitch-Verbin, D. Valenta, L. Baumrind, M. E. Pease and H. A. Quigley, "Retinal Glutamate Transporter Changes in Experimental Glaucoma and after Optic Nerve Transection in the Rat," Investigative Ophthalmology \& Visual Science, Vol. 43, No. 7, 2002, pp. 2236-2243.

[6] A. Bringmann, T. Pannicke, J. Grosche, M. Francke, P. Wiedemann, S. N. Skatchkov, N. N. Osborne and A. Reichenbach, "Muller Cells in the Healthy and Diseased Retina," Progress in Retinal and Eye Research, Vol. 25, No. 4, 2006, pp. 397-424. doi:10.1016/j.preteyeres.2006.05.003

[7] D. J. Holcombe, N. Lengefeld, G. A. Gole and N. L. Barnett, "The Effects of Acute Intraocular Pressure Elevation on Rat Retinal Glutamate Transport," Acta Ophthalmologica, Vol. 86, No. 4, 2008, pp. 408-414. doi:10.1111/j.1600-0420.2007.01052.x

[8] T. Rauen, W. R. Taylor, K. Kuhlbrodt and M. Wiessner, "High-Affinity Glutamate Transporters in the Rat Retina: A Major Role of the Glial Glutamate Transporter Glast-1 
in Transmitter Clearance," Cell and Tissue Research, Vol. 291, No. 1, 1998, pp. 19-31. doi:10.1007/s004410050976

[9] D. V. Pow and N. L. Barnett, "Changing Patterns of Spatial Buffering of Glutamate in Developing Rat Retinae Are Mediated by the Muller Cell Glutamate Transporter GLAST," Cell and Tissue Research, Vol. 297, No. 1, 1999, pp. 57-66. doi:10.1007/s004410051333

[10] T. Rauen and B. I. Kanner, "Localization of the Glutamate Transporter GLT-1 in Rat and Macaque Monkey Retinae," Neuroscience Letters, Vol. 169, No. 1-2, 1994 , pp. 137-140. doi:10.1016/0304-3940(94)90375-1

[11] T. Rauen, J. D. Rothstein and H. Wassle, "Differential Expression of Three Glutamate Transporter Subtypes in the Rat Retina," Cell and Tissue Research, Vol. 286, No. 3, 1996, pp. 325-336. doi:10.1007/s004410050702

[12] M. Wiessner, E. L. Fletcher, F. Fischer and T. Rauen, "Localization and Possible Function of the Glutamate Transporter, EAAC1, in the Rat Retina," Cell and Tissue Research, Vol. 310, No. 1, 2002, pp. 31-40. doi:10.1007/s00441-002-0612-1

[13] D. V. Pow and N. L. Barnett, "Developmental Expression of Excitatory Amino Acid Transporter 5: A Photoreceptor and Bipolar Cell Glutamate Transporter in Rat Retina," Neuroscience Letters, Vol. 280, No. 1, 2000, pp. 21-24. doi:10.1016/S0304-3940(99)00988-X

[14] N. L. Barnett and S. D. Grozdanic, "Glutamate Transporter Localization Does Not Correspond to the Temporary Functional Recovery and Late Degeneration after Acute Ocular Ischemia in Rats," Experimental Eye Research, Vol. 79, No. 4, 2004, pp. 513-524. doi:10.1016/j.exer.2004.06.022

[15] M. M. Ward, A. I. Jobling, T. Puthussery, L. E. Foster and E. L. Fletcher, "Localization and Expression of the Glutamate Transporter, Excitatory Amino Acid Transporter 4, within Astrocytes of the Rat Retina," Cell and Tissue Research, Vol. 315, No. 3, 2004, pp. 305-310. doi:10.1007/s00441-003-0849-3

[16] B. Fyk-Kolodziej, P. Qin, A. Dzhagaryan and R. G. Pourcho, "Differential Cellular and Subcellular Distribution of Glutamate Transporters in the Cat Retina," Visual Neuroscience, Vol. 21, No. 4, 2004, pp. 551-565. doi:10.1017/S0952523804214067

[17] A. Lee, A. R. Anderson, N. L. Barnett, M. G. Stevens and D. V. Pow, "Alternate Splicing and Expression of the Glutamate Transporter EAAT5 in the Rat Retina," Gene, Vol. 506, No. 2, 2012, pp. 283-288. doi:10.1016/j.gene.2012.07.010

[18] A. Lee, A. R. Anderson, S. J. Beasley, N. L. Barnett, P. Poronnik and D. V. Pow, "A New Splice Variant of the Glutamate-Aspartate Transporter: Cloning and Immunolocalization of GLAST1c in Rat, Pig and Human Brains," Journal of Chemical Neuroanatomy, Vol. 43, No. 1, 2012, pp. 52-63. doi:10.1016/j.jchemneu.2011.10.005

[19] G. A. Napper and M. Kalloniatis, "Neurochemical Changes Following Postmortem Ischemia in the Rat Retina," Visual Neuroscience, Vol. 16, No. 6, 1999, pp. 11691180. doi:10.1017/S0952523899166161
[20] N. L. Barnett, D. V. Pow, N. D. Bull, "Differential Perturbation of Neuronal and Glial Glutamate Transport Systems in Retinal Ischaemia," Neurochemistry International, Vol. 39, No. 4, 2001, pp. 291-299. doi:10.1016/S0197-0186(01)00033-X

[21] Q. Li and D. G. Puro, "Diabetes-Induced Dysfunction of the Glutamate Transporter in Retinal Muller Cells," Investigative Ophthalmology \& Visual Science, Vol. 43, No. 9, 2002, pp. 3109-3116.

[22] T. T. Lam, J. M. Kwong and M. O. Tso, "Early Glial Responses after Acute Elevated Intraocular Pressure in Rats," Investigative Ophthalmology \& Visual Science, Vol. 44, No. 2, 2003, pp. 638-645. doi:10.1167/iovs.02-0255

[23] N. N. Osborne, R. J. Casson, J. P. Wood, G. Chidlow, M. Graham and J. Melena, "Retinal Ischemia: Mechanisms of Damage and Potential Therapeutic Strategies," Progress in Retinal and Eye Research, Vol. 23, No. 1, 2004, pp. 91-147. doi:10.1016/j.preteyeres.2003.12.001

[24] M. Neuringer and W. E. Connor, "n-3 Fatty Acids in the Brain and Retina: Evidence for Their Essentiality," Nutrition Reviews, Vol. 44, No. 9, 1986, pp. 285-294. doi:10.1111/j.1753-4887.1986.tb07660.x

[25] N. G. Bazan, "Cell Survival Matters: Docosahexaenoic Acid Signaling, Neuroprotection and Photoreceptors," Trends in Neurosciences, Vol. 29, No. 5, 2006, pp. 263271. doi:10.1016/j.tins.2006.03.005

[26] N. G. Bazan, "Neuroprotectin D1-Mediated Anti-Inflammatory and Survival Signaling in Stroke, Retinal Degenerations, and Alzheimer's Disease," The Journal of Lipid Research, Vol. 50, 2009, pp. S400-S405. doi:10.1194/jlr.R800068-JLR200

[27] M. Neuringer, W. E. Connor, D. S. Lin, L. Barstad and S. Luck, "Biochemical and Functional Effects of Prenatal and Postnatal Omega 3 Fatty Acid Deficiency on Retina and Brain in Rhesus Monkeys," Proceedings of the $\mathrm{Na}$ tional Academy of Sciences of the United States of America, Vol. 83, No. 11, 1986, pp. 4021-4025. doi:10.1073/pnas.83.11.4021

[28] H. S. Weisinger, A. J. Vingrys, L. Abedin and A. J. Sinclair, "Effect of Diet on the Rate of Depletion of n-3 Fatty Acids in the Retina of the Guinea Pig," Journal of Lipid Research, Vol. 39, No. 6, 1998, pp. 1274-1279.

[29] G. J. Anderson, M. Neuringer, D. S. Lin and W. E. Connor, "Can Prenatal N-3 Fatty Acid Deficiency Be Completely Reversed after Birth? Effects on Retinal and Brain Biochemistry and Visual Function in Rhesus Monkeys,' Pediatric Research, Vol. 58, No. 5, 2005, pp. 865-872. doi:10.1203/01.pdr.0000182188.31596.5a

[30] C. L. Jensen, R. G. Voigt, T. C. Prager, Y. L. Zou, J. K. Fraley, J. C. Rozelle, M. R. Turcich, A. M. Llorente, R. E. Anderson and W. C. Heird, "Effects of Maternal Docosahexaenoic Acid Intake on Visual Function and Neurodevelopment in Breastfed Term Infants," The American Journal of Clinical Nutrition, Vol. 82, No. 1, 2005, pp. 125-132.

[31] K. Moriguchi, T. Yuri, K. Yoshizawa, K. Kiuchi, H. Takada, Y. Inoue, T. Hada, M. Matsumura and A. Tsubura, "Dietary Docosahexaenoic Acid Protects against N-Me- 
thyl-N-nitrosourea-Induced Retinal Degeneration in Rats," Experimental Eye Research, Vol. 77, No. 2, 2003, pp. 167-173. doi:10.1016/S0014-4835(03)00114-3

[32] A. Garelli, N. P. Rotstein and L. E. Politi, "Docosahexaenoic Acid Promotes Photoreceptor Differentiation without Altering Crx Expression," Investigative Ophthalmology \& Visual Science, Vol. 47, No. 7, 2006, pp. 30173027. doi:10.1167/iovs.05-1659

[33] O. Miyauchi, A. Mizota, E. Adachi-Usami and M. Nishikawa, "Protective Effect of Docosahexaenoic Acid against Retinal Ischemic Injury: An Electroretinographic Study," Ophthalmic Research, Vol. 33, No. 4, 2001, pp. 191-195. doi:10.1159/000055669

[34] K. Murayama, S. Yoneya, O. Miyauchi, E. Adachi-Usami and M. Nishikawa, "Fish Oil (Polyunsaturated Fatty Acid) Prevents Ischemic-Induced Injury in the Mammalian Retina," Experimental Eye Research, Vol. 74, No. 6, 2002, pp. 671-676. doi:10.1006/exer.2002.1151

[35] J. D. Moreira, L. Knorr, M. Ganzella, A. P. Thomazi, C. G. de Souza, D. G. de Souza, C. F. Pitta, T. Mello e Souza, S. Wofchuk, E. Elisabetsky, L. Vinade, M. L. Perry and D. O. Souza, "Omega-3 Fatty Acids Deprivation Affects Ontogeny of Glutamatergic Synapses in Rats: Relevance for Behavior Alterations," Neurochemistry International, Vol. 56, No. 6-7, 2010, pp. 753-759. doi:10.1016/j.neuint.2010.02.010

[36] J. C. Dreixler, A. R. Shaikh, M. Alexander, B. Savoie and S. Roth, "Post-Ischemic Conditioning in the Rat Retina Is Dependent Upon Ischemia Duration and Is Not Additive with Ischemic Pre-Conditioning," Experimental Eye Research, Vol. 91, No. 6, 2010, pp. 844-852. doi:10.1016/j.exer.2010.06.015

[37] T. Pannicke, I. Iandiev, O. Uckermann, B. Biedermann, F. Kutzera, P. Wiedemann, H. Wolburg, A. Reichenbach and A. Bringmann "A Potassium Channel-Linked Mecha- nism of Glial Cell Swelling in the Postischemic Retina," Molecular and Cellular Neuroscience, Vol. 26, No. 4, 2004, pp. 493-502. doi:10.1016/j.mcn.2004.04.005

[38] C. K. Park, J. Cha, S. C. Park, P. Y. Lee, J. H. Kim, H. S. Kim, S. A. Kim, I. B. Kim and M. H. Chun, "Differential Expression of Two Glutamate Transporters, GLAST and GLT-1, in an Experimental Rat Model of Glaucoma," Experimental Brain Research, Vol. 197, No. 2, 2009, pp. 101-109. doi:10.1007/s00221-009-1896-0

[39] T. Harada, C. Harada, K. Nakamura, H. M. Quah, A. Okumura, K. Namekata, T. Saeki, M.Aihara, H. Yoshida, A. Mitani and K. Tanaka, "The Potential Role of Glutamate Transporters in the Pathogenesis of Normal Tension Glaucoma," Journal of Clinical Investigation, Vol. 117, No. 7, 2007, pp. 1763-1770. doi:10.1172/JCI30178

[40] K. Namekata, C. Harada, X. Guo, K. Kikushima, A. Kimura, N. Fuse, Y. Mitamura, K. Kohyama, Y. Matsumoto, K. Tanaka and T. Harada, "Interleukin-1 Attenuates Normal Tension Glaucoma-Like Retinal Degeneration in EAAC1-Deficient Mice," Neuroscience Letters, Vol. 465, No. 2, 2009, pp. 160-164. doi:10.1016/j.neulet.2009.09.029

[41] J. L. Arriza, S. Eliasof, M. P. Kavanaugh, S. G. Amara, "Excitatory Amino Acid Transporter 5, a Retinal Glutamate Transporter Coupled to a Chloride Conductance," Proceedings of the National Academy of Sciences of the United States of America, Vol. 94, No. 8, 1997, pp. 41554160.

[42] E. Wersinger, Y. Schwab, J. A. Sahel, A. Rendon, D. V. Pow, S. Picaud and M. J. Roux, "The Glutamate Transporter EAAT5 Works as a Presynaptic Receptor in Mouse Rod Bipolar Cells," The Journal of Physiology, Vol. 577, No. , 2006, pp. 221-234.

[43] R. D. O'Brien, 2004 "Fats and Oils: Formulating and Processing for Application," 2nd Edition, CRC Press, USA.

\section{Abbreviations List}

CNS - central nervous system; DHA-docosahexaenoic acid; EAAC1 - excitatory amino acids transporter $\mathrm{C} 1$; EAAT4 - excitatory amino acids transporter 4; EAAT5 — excitatory amino acids transporter 5; GLAST—glutamate transporter; GLT-1 - glutamate transporter; HBSSHank's balanced salt solution; HIOP - high intraocular pressure; PUFA - polyunsaturated fatty acids; SDSPAGE - sodium dodecyl sulfate polyacrylamide gel electrophoresis; $\omega 3$-omega-3 fatty acids. 